\title{
Important amino acid residues of potato plant uncoupling protein (StUCP)
}

P. Ježek ${ }^{1}$,

A.D.T. Costa ${ }^{2}$ and A.E. Vercesi ${ }^{2}$

\author{
${ }^{1}$ Department of Membrane Transport Biophysics, Institute of Physiology, \\ Academy of Science, Prague, Czech Republic \\ ${ }^{2}$ Departamento de Patologia Clínica (NMCE), Faculdade de Ciências M édicas, \\ Universidade Estadual de Campinas, Campinas, SP, Brasil
}

\author{
Correspondence \\ A.E. Vercesi \\ Departamento de Patologia Clínica \\ (NMCE), FCM, UNICAMP \\ Caixa Postal 6111 \\ 13083-970 Campinas, SP \\ Brasil \\ Fax: + 55-19-788-1118 \\ E-mail: anibal@obelix.unicamp.br \\ Research supported by PRO NEX, \\ FAPESP, CNPq and PADCT/CNPq. \\ A.D.T. Costa was the recipient of a \\ FAPESP fellowship. Some chemicals \\ were purchased through a grant \\ (N o. 301/98/0568) from the Grant \\ Agency of the Czech Republic.
}

Received April 28, 2000 Accepted September 13, 2000

\section{Abstract}

Chemical modifications were used to identify some of the functionally important amino acid residues of the potato plant uncoupling protein $(S t \mathrm{UCP})$. The proton-dependent swelling of potato mitochondria in $\mathrm{K}^{+}$-acetate in the presence of linoleic acid and valinomycin was inhibited by mersalyl $\left(K_{\mathrm{i}}=5 \mu \mathrm{M}\right)$ and other hydrophilic SH reagents such as Thiolyte MB, iodoacetate and 5,5'-dithio-bis-(2-nitrobenzoate), but not by hydrophobic N-ethylmaleimide. This pattern of inhibition by $\mathrm{SH}$ reagents was similar to that of brown adipose tissue uncoupling protein (UCP1). As with UCP1, the arginine reagent 2,3-butadione, but not N-ethylmaleimide or other hydrophobic SH reagents, prevented the inhibition of StUCP-mediated transport by ATP in isolated potato mitochondria or with reconstituted $S t \mathrm{UCP}$. The results indicate that the most reactive amino acid residues in UCP1 and StUCP are similar, with the exception of $\mathrm{N}$-ethylmaleimide-reactive cysteines in the purine nucleotide-binding site.

\section{Introduction}

The functionally well-characterized plant uncoupling mitochondrial protein (PUMP) (113) has been cloned from potato (StUCP) (14) and Arabidopsis thaliana (AtPUMP) (15) gene libraries. We provided evidence that potato PUMP is a product of the StUCP gene (16). Consequently, PUMP has been recognized as a member of the uncoupling protein (UCP) subfamily, homologous with mammalian UCPs such as UCP1 of brown adipose tissue mitochondria (2,17-19), the ubiquitous UCP2 (20), UCP3 of striated muscle (21), and two brainspecific uncoupling proteins, UCP4 (22) and BMCP1 (23). The physiological roles of UCPs in mammals include nonshivering thermogenesis in neonates (UCP1), regulation of weight balance and inflammatory responses such as fever (UCP2), nonshivering thermogenesis in skeletal muscle (UCP3), and possibly the prevention or regulation of apoptosis in the brain (UCP4, BMCP1). We have hypothesized (2,46) that, in plants, StUCP may be responsible for a respiratory burst in climacteric fruits and for all physiological events when a sudden cessation of ATP synthesis is required such as during seed formation and senescence. Several climacteric fruits such as tomato (7), banana, mango, apple and others (2) contain StUCP. A mild thermogenesis mediated by $S t \mathrm{UCP}$ can accelerate respiration and, hence, metabolic rates (2) and mild $S t \mathrm{UCP}$-mediated uncoupling leads to a decreased formation of reactive oxygen species (8). Both functions are beneficial for plant growth and development. Thus, fully activated thermogenesis could facilitate plant growth at low temperature, e.g., in roots, tubers (9), or during seed germination. StUCP may also play specific roles during 
plant senescence and could contribute to processes that maintain the seed dormancy.

All UCPs presumably enable the passage of fatty acid (FA) anions and thus promote FA cycling, leading to $\mathrm{H}^{+}$uniport mediated by neutral FA molecules, which results in uncoupling $(2,19,24,25)$. The FA cycling mechanism has been confirmed for UCP1 (26), UCP2 and UCP3 (24) and StUCP (6). UCP1 also translocates a wide variety of monovalent, unipolar anions, including short-, medium-, and long-chain alkylsulfonates (27). Hexane and undecanesulfonate transport has also been demonstrated for StUCP $(5,6)$. Nevertheless, $S t \mathrm{UCP}$ is not able to translocate small hydrophilic anions such as $\mathrm{Cl}^{-}$and pyruvate $(5,6)$ which are good transport substrates for UCP1 $(2,19$, 27,28).

The protein chemistry of $S t \mathrm{UCP}$ has not been studied to the same extent as has UCP1. A 32-kDa $S t \mathrm{UCP}$ has been characterized as a hydrophobic protein which is not retained on hydroxylapatite in the detergent micellar solution $(1,6,7)$. Chemical modifications of reactive amino acid residues, the cleavage pattern produced by proteases, and ligand binding (except for studies with 8azido-ATP (13)) have not been studied in StUCP. In the present study, we examined the effects of several chemical modifiers on $S t \mathrm{UCP}$-mediated transport as well as $S t \mathrm{UCP}$ inhibition by purine nucleotides. Our results clearly show that the pattern of reactive amino acid residues in $S t \mathrm{UCP}$ is similar to that of UCP1, with the exception that no N-ethylmaleimide (NEM)-reactive cysteines were found in the purine nucleotide-binding site of $S t \mathrm{UCP}$.

\section{Material and Methods}

\section{Biological material and chemicals}

Potatoes (Solanum tuberosum, L. cv. Bintje) were purchased locally. Nucleotides, bovine serum albumin (BSA), valinomycin, nigericin, iodoacetate, linoleic acid, N-tris [hydroxymethyl]methyl-2-aminoethanesulfonic acid (TES), N-[2-hydroxyethyl]piperazine-N'-[2-ethane] sulfonic acid (HEPES), tetraethylammonium hydroxide (TEA-OH), carbonyl cyanide trifluoromethoxyphenylhydrazone (FCCP), ethylene glycol-bis(ßaminoethyl ether) N,N,N',N'-tetraacetic acid (EGTA), ethylenediaminetetraacetic acid (EDTA), 5,5'-dithio-bis-(2-nitrobenzoate) (DTNB), 4,4'-diisothiocyanatostilbene-2,2'disulfonic acid (DIDS), 2,4,6-trinitrobenzenesulfonic acid (TNBS), pyridoxalphosphate, phenylglyoxal, propranolol, phenylarsineoxide, eosinmaleimid, 2,3-butadione and phospholipids were purchased from Sigma Chemical Co. (St. Louis, MO, USA). The fluorescent probe SPQ (6-methoxy-N-(3sulfopropyl) quinolinium) and thiol reagent Thiolyte $^{\circledR}$ MB were from Calbiochem (La Jolla, CA, USA). The potassium probe PBFI (potassium-binding benzofuraneisophthalate) was from Molecular Probes (Eugene, OR, USA). All other reagents were commercial products of the purest grade available.

\section{Isolation of mitochondria and protein determination}

Potato mitochondria were isolated as described previously $(5,8,9)$ in medium containing $250 \mathrm{mM}$ sucrose, $10 \mathrm{mM}$ HEPES, $\mathrm{pH}$ 7.2 , and $0.3 \mathrm{mM}$ EGTA. The protein concentration was $30-40 \mathrm{mg} / \mathrm{ml}$, as determined by the biuret method. A crude fraction was used for swelling studies and for most of the isolations. For some isolations, a Percoll gradient centrifugation was used to remove contamination by plastid proteins, starch and other substances. Qualitatively, transport measurements using the crude fraction gave identical results as those performed with Percoll-purified mitochondria.

\section{Swelling assay of StU CP transport function}

Proton-dependent swelling of potato mi- 
tochondria $(0.2 \mathrm{mg}$ protein $/ \mathrm{ml})$ in $\mathrm{K}^{+}$-acetate $\left(55 \mathrm{mM} \mathrm{K}^{+}\right.$-acetate, $5 \mathrm{mM} \mathrm{K}^{+}$-HEPES, 0.2 $\mathrm{mM}$ Tris-EDTA, $0.1 \mathrm{mM}$ Tris-EGTA, $\mathrm{pH}$ 6.9) initiated by valinomycin in the presence of linoleic acid $(16 \mu \mathrm{M})$ has been used as a standard assay for StUCP-mediated transport (5). Since valinomycin allows the uniport uptake of $\mathrm{K}^{+}$and neutral acetic acid is able to penetrate the lipid bilayer, an efflux of $\mathrm{H}^{+}$is necessary to induce swelling. In our assay, this $\mathrm{H}^{+}$efflux was concomitant with linoleic acid cycling which allowed swelling since $S t$ UCP mediated the uptake of linoleic acid anion, while protonated linoleic acid passed spontaneously through the lipid bilayer by a flip-flop mechanism and released $\mathrm{H}^{+}$externally. Hexanesulfonate uniport was assayed as valinomycin-induced swelling in medium containing $51.1 \mathrm{mM} \mathrm{Na}{ }^{+}$-hexanesulfonate, $30.8 \mathrm{mM} \mathrm{K}^{+}$-HEPES, pH 7.2, $190 \mu \mathrm{M}$ TrisEDTA and $95 \mu \mathrm{M}$ Tris-EGTA. The side effects caused by the chemical modifiers used, including the induction of mitochondrial swelling without the addition of ionophore and membrane stiffening, were controlled by performing a swelling assay in $\mathrm{K}^{+}-$ acetate containing nigericin, which does not depend on protein carriers. When a decrease in this rate $\left(\mathrm{v}_{\mathrm{Nig}}[\mathrm{c}]\right)$ was observed at a given concentration [c] of modifier, the rates of valinomycin-induced $S t \mathrm{UCP}$-mediated swelling were corrected by multiplying this decrease by the factor $\mathrm{v}_{\mathrm{Nig}}[\mathrm{c}=0] / \mathrm{v}_{\mathrm{Nig}}[\mathrm{c}]$.

\section{Chemical modifications of potato mitochondria}

For carrying reactions, mitochondria were resuspended in the sucrose isolation medium $(5 \mathrm{mg}$ protein $/ \mathrm{ml})$ and aliquots of stock solutions (aqueous or in dimethylsulfoxide) of various reagents were added and incubated for $1 \mathrm{~h}$ (unless otherwise indicated) at $0^{\circ} \mathrm{C}$. For NEM, DTNB and phenylglyoxal, $\mathrm{pH}$ was raised to 8.2 by adding $20 \mathrm{mM}$ TrisHEPES, $\mathrm{pH} 8.4$, to the stock solution and 2 $\mu \mathrm{M}$ propranolol was added.

\section{StUCP isolation and reconstitution}

StUCP was isolated from potato mitochondria on hydroxylapatite as described previously (6). The same procedure was used for the isolation of potato mitochondria pretreated with Thiolyte MB or 2,3-butadione. Thirty micrograms of isolated StUCP was incorporated into liposomes by detergent removal using Bio-Beads SM2 (BioRad, Hercules, CA, USA) and the vesicles were depleted of the external probe by passage through Sephadex G25-300 spin columns (6). The FA-induced $\mathrm{H}^{+}$fluxes initiated by valinomycin were monitored either as the counterflux of $\mathrm{K}^{+}$, using PBFI $(6,7)$, or by TES anion quenching of SPQ, as described previously $(6,7)$, on an F4010 Hitachi fluorescence spectrophotometer (Hitachi Ltd., Tokyo, Japan). For PBFI monitoring, the vesicles ( $25 \mu \mathrm{l}$ per assay) contained $75 \mathrm{mM}$ TEA sulfate, $75 \mathrm{mM}$ TEA-TES, $\mathrm{pH}$ 7.2, $0.05 \mathrm{mM} \mathrm{K}_{2} \mathrm{SO}_{4}$ and $300 \mu \mathrm{M}$ PBFI. The external medium contained $75 \mathrm{mMK}_{2} \mathrm{SO}_{4}$ and 75 mM TEA-TES, pH 7.2. For SPQ monitoring, the vesicles ( $25 \mu 1$ per assay) contained 84.4 mM TEA sulfate, $28.85 \mathrm{mM}$ TEA-TES, pH 7.2 ([TEA] was $9.2 \mathrm{mM}$ ) and $0.6 \mathrm{mM}$ TrisEGTA. In the external medium, $84.4 \mathrm{mM}$ $\mathrm{K}_{2} \mathrm{SO}_{4}$ replaced TEA sulfate.

\section{Results}

\section{Effect of hydrophilic SH reagents on StUCP- mediated transport in mitochondria}

Proton-dependent swelling of potato mitochondria initiated by valinomycin in $\mathrm{K}^{+}$-acetate containing linoleic acid was reversibly inhibited by the organomercurial $\mathrm{SH}$ reagent mersalyl with an apparent $K_{\mathrm{i}}$ of $5 \mu \mathrm{M}$ (Figure 1A, only 10 -s preincubations). This type of swelling reflected the ability of StUCP to translocate linoleic acid anions (5). The effect of mersalyl can be considered as a specific inhibition, since swelling independent of a protein carrier, i.e., the nigericin-induced swelling in $\mathrm{K}^{+}$-acetate, was not affected up to $100 \mu \mathrm{M}$ 
mersalyl (Figure 1A). Above $100 \mu \mathrm{M}$, and above $40 \mu \mathrm{M}$ in the presence of linoleic acid, mersalyl induced nonspecific permeability changes which were observed as mitochondrial swelling without the ionophore. Some mitochondrial preparations were more sensitive to mersalyl and this made measurements with them more difficult.

To avoid the interference of nonspecific permeability changes, we used Thiolyte MB, a covalently interacting SH modifier. Mitochondria were preincubated for $1 \mathrm{~h}$ with increasing Thiolyte MB doses (Figure 2). The $\mathrm{IC}_{50}$ for Thiolyte MB was around $500 \mathrm{nmol} / \mathrm{mg}$ protein. Carrier-independent swelling was not significantly affected by Thiolyte MB, indicating that the modification of the $\mathrm{SH}$ groups in

Figure 1 - Inhibition of protondependent swelling of potato mitochondria by mersalyl $(A)$ and iodoacetic acid (B) in $\mathrm{K}^{+}$-acetate buffer. The inhibition by mersalyl of StUCP-mediated transport (filled circles) and nigericin-mediated, protein-independent swelling (open squares) are specific and nonspecific effects of mersalyl, respectively. The solid line represents the fit of the data us-

ing the Hill equation with a Hill coefficient of 2 , yielding an apparent $K_{i}$ of $5 \mu \mathrm{M}$. B, The iodoacetate dose-response curve, yielding an $\mathrm{IC}_{50}$ around $100 \mu \mathrm{mol} / \mathrm{mg}$ protein, has already been corrected for the nonspecific effect produced by this compound. The correction and other details of the measurements are described in Material and Methods.

Figure 2 - Inhibition of protondependent swelling of potato mitochondria by Thiolyte MB in $\mathrm{K}^{+}$-acetate buffer. The points show the specific effect of Thiolyte MB on StUCP-mediated transport in potato mitochondria (squares) and the negligible, nonspecific effect on nigericin-mediated, protein-independent swelling (diamonds). The solid line represents the best fit curve for the data, when omitting the fourth point. Further details of the measurements are described in Material and Methods.
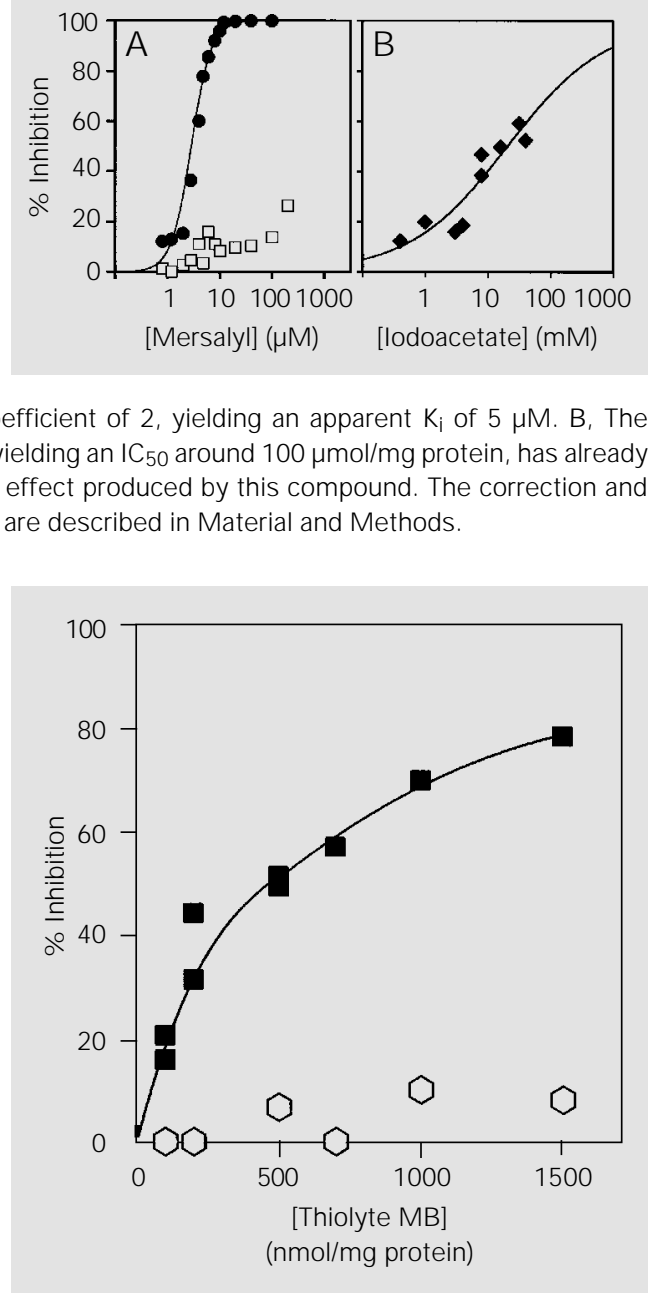

StUCP inhibits the transport activity of this protein. Carboxymethylation by iodoacetate (which also affects $\mathrm{SH}$ groups) also inhibited $S t \mathrm{UCP}$ transport activity at higher doses $\left(\mathrm{IC}_{50}\right.$ of $100 \mu \mathrm{mol} / \mathrm{mg}$ protein), but only with $10-\mathrm{s}$ preincubations (Figure 1B). Ellman's reagent (DTNB) inhibited the activity by 18 and $31 \%$ at 1000 and $3000 \mathrm{nmol} / \mathrm{mg}$ protein, respectively, after a 2-h incubation, as calculated from the rates corrected for the nonspecific effect (incubations at $\mathrm{pH}>8$ lead to preswelling after a few hours). In contrast, NEM and other hydrophobic SH reagents (eosinmaleimide, phenylarsineoxide) were not inhibitory up to $10 \mu \mathrm{mol} / \mathrm{mg}$ protein. Hexanesulfonate uniport via $S t \mathrm{UCP}$ was partially inhibited by hydrophilic SH reagents, e.g., by $1000 \mathrm{nmol}$ Thiolyte $\mathrm{MB} / \mathrm{mg}$ protein.

\section{Effect of arginine reagents on ATP inhibition of StU CP-mediated transport}

Reagents specific for other amino acid residues did not inhibit transport or prevent the inhibition by ATP at doses up to $10 \mu \mathrm{mol} / \mathrm{mg}$ protein. The reagents tested included DIDS, TNBS and lysine-specific pyridoxalphosphate. Only an arginine-specific reagent, 2,3-butadione, completely prevented the inhibition of linoleic acid transport by $4 \mathrm{mM}$ ATP (Figure 3) at doses above $100 \mathrm{nmol} / \mathrm{mg}$ protein (see inset in Figure 3). Thus, a 1-h incubation with $4000 \mathrm{nmol} / \mathrm{mg}$ protein 2,3-butadione shifted the ATP dose-response curve so that the extrapolated apparent $K_{\mathrm{i}}$ was much greater than $10 \mathrm{mM}$ (Figure 3). Surprisingly, phenylglyoxal, a more bulky arginine reagent, had no effect at doses up to $10 \mu \mathrm{mol} / \mathrm{mg}$ protein. NEM, which prevented nucleotide inhibition of UCP, also had no effect on ATP inhibition of StUCP (data not shown).

\section{Confirmation of the effects of 2,3-butadione and Thiolyte MB using reconstituted StUCP}

The effect of 2,3-butadione on StUCP reconstituted into proteoliposomes after 
premodification by 2,3-butadione in mitochondria was identical to that found in potato mitochondria. 2,3-Butadione prevented purine nucleotide inhibition of $\mathrm{H}^{+}$efflux, including inhibition by GTP, when the $\mathrm{H}^{+}$ efflux was monitored with the fluorescent probe $\mathrm{PBFI}$ concomitant with $\mathrm{K}^{+}$influx (Figure 4). The inhibitory effect of Thiolyte MB was also confirmed for isolated StUCP reconstituted into liposomes for which linoleic acid uniport or concomitant $\mathrm{H}^{+}$efflux was detected by TES quenching of the fluorescent probe SPQ (Figure 5). Reconstituted Thiolyte MB-modified StUCP showed no transport activity (Figure 5).

\section{Discussion}

The pattern of reactive amino acid residues in $S t \mathrm{UCP}$ was surprisingly similar to that of mammalian UCP1 (29-33; for reviews, see 17-19). This similarity suggests that the structures of StUCP and UCP1 are very likely to be closely related, despite only about $40 \%$ identity in their sequences $(14,15)$.

The chemical modification of reactive amino acid residues in proteins has been widely used to study protein structure/function relationships. Site-directed mutagenesis has shown that the identification of a residue as essential for a given function is not a straightforward task. In many cases, the effects of modifiers differ from the phenotypes of the corresponding substitution mutants. Interference by the reagent and/or the mutation with the protein function may indicate that i) the residue is essential for that function, i.e., is involved in the required functional interactions (in this case, the substitution mutants have an identical phenotype), ii) the modification of the residue produces steric hindrances which are the actual cause of the altered function (substitution mutations show no such effect), or iii) the residue is important for maintaining a proper conformation of the protein and cannot retain this position after being modified or mutated.
With UCP1, case (i) is valid for its Arg 276, whereas case (ii) has been indicated for its cysteine residues.

When Arg 276 was either substituted in a mutated UCP1 protein (34) or modified by phenylglyoxal and 2,3-butadione (32), purine nucleotide binding and gating were $a b-$ sent. Since the proximal third matrix segment was photolabeled at three different positions with 8-azido-, 2-azido- and 3'-O(5-fluoro-2,4-dinitrophenyl) adenosine 5'triphosphate (FNDP-ATP) (35), and since the deletion of residues 261-269 resulted in the lack of nucleotide inhibition (36), it was concluded that the main location of the nucleotide-binding site in UCP1 was located between the fifth and sixth transmembrane segments. This site probably forms a waterfilled cavity which penetrates deeply into the membrane close to the opposite surface (35). This cavity in UCP1 is lined with SH residues (C213, C224, C253, C287, C304, and possibly $\mathrm{C} 188$ ). Studies on these residues identified the case (ii) described above, since SH substitution mutants of UCP1 have no disrupted binding or transport (33).

The modification of UCP1 by hydrophobic and hydrophilic SH reagents drastically reduces inhibition by GDP (31). In contrast to UCP1, NEM did not prevent ATP inhibition of transport in $S t \mathrm{UCP}$. However, trans-

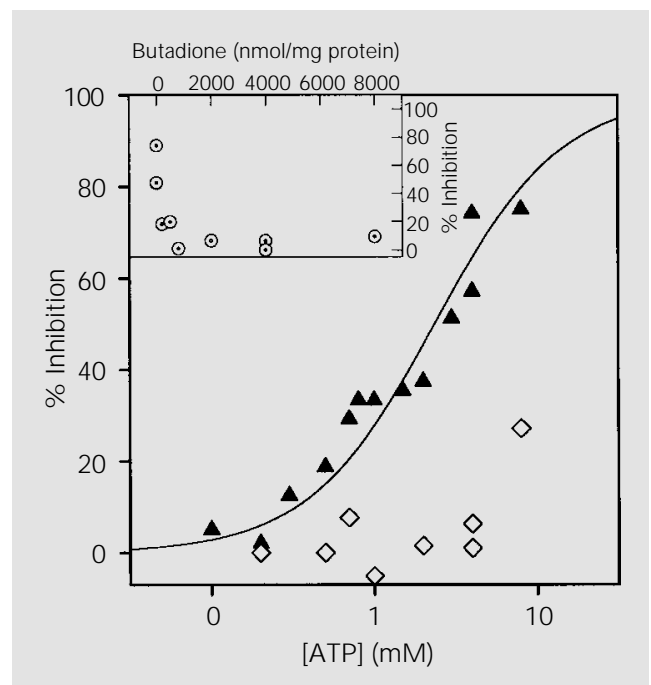

Figure 3 - Prevention of ATP inhibition of StUCP-mediated transport following modification of potato mitochondria with 2,3butadione. The inhibition by ATP of StUCP-mediated proton-dependent swelling in $\mathrm{K}^{+}$-acetate buffer vs log [ATP] is shown for unmodified potato mitochondria (triangles) and mitochondria premodified with $4000 \mathrm{nmol} / \mathrm{mg}$ protein 2,3-butadione (diamonds). Inset, Inhibition by 4 mM ATP vs butadione dose in the preincubations. The assay conditions are described in $\mathrm{Ma}$ terial and Methods. 

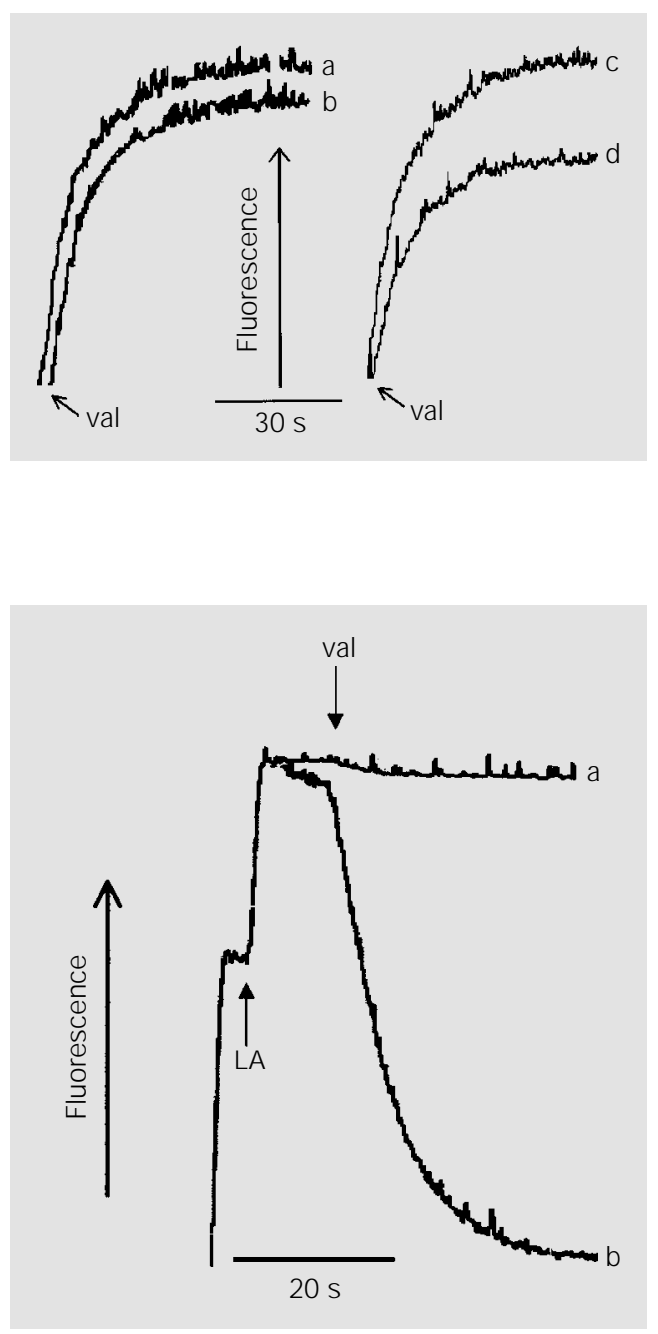

port was inhibited by the arginine reagent 2,3-butadione. These findings suggest a probable difference between the purine nucleotide-binding site of UCP1 and StUCP and indicate that $S t \mathrm{UCP}$ does not contain modifiable SH groups at or close to the nucleotidebinding site. Alternatively, SH groups may not be important for maintaining the integrity of StUCP conformation. These findings agree with the amino acid sequence of potato plant UCP $(14,16)$. Thus, C188 of UCP1 is conserved in UCP2 and UCP3, but is substituted by A197 in StUCP (14). Of the two cysteines conserved in the fifth $\alpha$-helix of UCP1, 2 and 3, the first, C234, is shifted two residues towards the matrix in $S t \mathrm{UCP}$ such
Figure 4 - Lack of inhibition by GTP in proteoliposomes containing StUCP from mitochondria modified by $2,3-$ butadione. $\mathrm{H}^{+}$efflux induced by $1.3 \mu \mathrm{M}$ valinomycin (val) in the presence of $53 \mu \mathrm{M}$ linoleic acid was monitored using the fluorescent probe PBFI to measure the concomitant $\mathrm{K}^{+}$influx in proteoliposomes containing StUCP isolated from mitochondria modified by 2,3butadione (4000 nmol/mg protein) (traces a,b). The responses of unmodified, reconstituted StUCP (control) are also shown (traces $c, d$ ). Traces a,c: No further additions; traces b,d: addition of $4 \mathrm{mM}$ Tris-GTP. Vesicles ( $25 \mu$ per assay) contained $75 \mathrm{mM}$ TEA sulfate, $75 \mathrm{mM}$ TEA-TES, pH 7.2, $0.05 \mathrm{mM} \mathrm{K}_{2} \mathrm{SO}_{4}$ and 300 $\mu \mathrm{M}$ PBFI. The external medium contained $75 \mathrm{mM}$ $\mathrm{K}_{2} \mathrm{SO}_{4}$ and 75 mM TEA-TES, pH 7.2.

Figure 5 - Lack of $\mathrm{H}^{+}$efflux in proteoliposomes containing Thiolyte MB-modified StUCP. StUCP from mitochondria treated with Thiolyte MB $(1000 \mathrm{nmol} / \mathrm{mg}$ protein) were isolated and reconstituted into vesicles (trace a). The response of normal reconstituted StUCP (control) is shown in trace b. $\mathrm{H}^{+}$efflux was monitored by TES quenching of the fluorescent probe SPQ. The addition of $53 \mu \mathrm{M}$ linoleic acid (LA) caused internal acidification of the vesicles, resulting in the flip-flop of neutral fatty acids into the inner lipid leaflet and subsequent dissociation in the internal medium. StUCP function was seen as an $\mathrm{H}^{+}$efflux (internal alkalinization, indicated by the decrease in SPQ fluorescence), initiated by $1.3 \mu \mathrm{M}$ valinomycin (val). This efflux was suppressed in Thiolyte MB-modified samples. Vesicles $(25 \mu \mathrm{l}$ per assay) contained $84.4 \mathrm{mM}$ TEA sulfate, $28.85 \mathrm{mM}$ TEATES, pH 7.2, ([TEA] was $9.2 \mathrm{mM}$ ) and $0.6 \mathrm{mM}$ TrisEGTA. In the external medium, $84.4 \mathrm{mM} \mathrm{K}_{2} \mathrm{SO}_{4}$ replaced TEA sulfate.

that its position in the $\alpha$-helix is occupied by F231. The second $\mathrm{SH}(\mathrm{C} 213$ of UCP1) is not conserved in StUCP and is substituted by T220. The similarity of the purine nucleotide-binding site in StUCP and UCP1 is reflected by the effect of 2,3-butadione, which probably interacts with the conserved arginines in UCPs (and in the mitochondrial carrier gene family as a whole), such as R276 of UCP1 (37), which corresponds to $\mathrm{R} 281$ and $\mathrm{R} 278$ in $S t \mathrm{UCP}$ and $A t \mathrm{UCP}$, respectively $(14,15)$.

Hydrophilic, but not hydrophobic, SH reagents were good inhibitors of UCP1-mediated FA-induced $\mathrm{H}^{+}$transport (30). Similarly, in StUCP only hydrophilic SH reagents 
inhibited StUCP-mediated transport of linoleic acid and hexanesulfonate, while hydrophobic SH reagents, arginine, lysine and other modifiers had no effect. Hence, inhibition by hydrophilic SH reagents is common to StUCP and UCP1. This inhibitory effect on UCP1 has not yet been fully explained. The SH groups which maintain the integrity of the translocation pathway or, alternatively, participate directly in the translocation mechanism, are probably distinct from those interacting with NEM (in UCP1) and interfere with nucleotide binding after modification
(31). These $\mathrm{SH}$ groups are probably located at yet unknown similar positions in the $S t \mathrm{UCP}$ sequence. In addition, the type of interference by SH reagents with the StUCP translocation mechanism is likely to be the same as for UCP1. A possible candidate for such a residue is $\mathrm{C} 90$, located in the second $\alpha$-helix of StUCP, which does not have any counterpart in the sequences of UCP1, 2 and 3. Residue C24 of UCP1, absent in StUCP, may serve a similar function for $\mathrm{C} 90$ in $S t \mathrm{UCP}$.

\section{References}

1. Vercesi AE, Martins IS, Silva MAP, Leite HMF, Cuccovia IM \& Chaimovich $\mathrm{H}$ (1995). PUM Ping plants. Nature, 375: 24.

2. J ežek $P$, Engstová $H$, Žácková $M$, Vercesi $A E$, Costa ADT, Arruda $P \&$ Garlid KD (1998). Fatty acid cycling mechanism and mitochondrial uncoupling proteins. Biochimica et Biophysica Acta, 1365: 319327.

3. Vercesi $A E$, Chaimovich $H \&$ Cuccovia IM (1997). A plant uncoupling mitochondrial protein, PUMP. Recent Research Development in Plant Physiology, 1: 85-91.

4. Vercesi $A E$, Ježek $P$, Costa ADT, Kowaltowski AJ, Maia IG \& Arruda P (1998). A plant uncoupling mitochondrial protein. In: Moller IM, Gardestrom P, Glimelius K \& Glaser E (Editors), Plant Mitochondria: From Gene to Function. Backhuys Publishers, Leiden, The Netherlands, 435-440.

5. J ežek P, Costa ADT \& Vercesi AE (1996). Evidence for anion-translocating plant uncoupling mitochondrial protein in potato mitochondria. J ournal of Biological Chemistry, 271: 32743-32748.

6. J ežek P, Costa ADT \& Vercesi AE (1997). Reconstituted plant uncoupling mitochondrial protein allows for proton translocation via fatty acid cycling mechanism. J ournal of Biological Chemistry, 272: 24272-24278.

7. Costa ADT, Nantes IL, J ežek $P$, Leite $A$, Arruda P \& Vercesi AE (1999). Plant uncoupling mitochondrial protein activity in mitochondria isolated from tomatoes at different stages of ripening. J ournal of Bioenergetics and Biomembranes, 31: 527-533.

8. Kowaltowski AJ , Costa ADT \& Vercesi AE
(1998). Activation of the potato plant uncoupling mitochondrial protein inhibits reactive oxygen species generation by the respiratory chain. FEBS Letters, 425: 213216.

9. Nantes IL, Fagian MM, Catisti R, Arruda P, Maia IG \& Vercesi AE (1999). Low temperature- and aging-promoted expression of PUMP in potato tuber mitochondria. FEBS Letters, 457: 103-106.

10. Sluse FE, Almeida AM, J armuszkiewicz W \& Vercesi AE (1998). Free fatty acids regulate the uncoupling protein and alternative oxidase activities in plant mitochondria. FEBS Letters, 433: 237-240.

11. J armuszkiewicz W, Almeida AM, SluseGoffart C, Sluse FE \& Vercesi AE (1998). Linoleic acid-induced activity of plant uncoupling mitochondrial protein in purified tomato fruit mitochondria during resting, phosphorylating, and progressively uncoupled respiration. J ournal of Biological Chemistry, 273: 34882-34886.

12. Almeida AM, J armuszkiewicz W, Khomsi H, Arruda P, Vercesi AE \& Sluse FE (1999). Cyanide-resistant, ATP-synthesis-sustained, and uncoupling-protein-sustained respiration during postharvest ripening of tomato fruit. Plant Physiology, 119: 13231330.

13. Saviani EE, da Silva Jr A \& Martins IS (1997). Photoaffinity labelling of the uncoupling protein from potato tuber mitochondria. Plant Physiology and Biochemistry, 35: 701-706.

14. Laloi $M$, Klein $M$, Reismeier J W, MüllerRöber B, Fleury C, Bouillaud $\mathrm{F} \&$ Ricquier $D$ (1997). A plant cold-induced uncoupling protein. Nature, 389: 135-136.

15. Maia IG, Benedetti CE, Leite A, Turcinelli
SR, Vercesi AE \& Arruda P (1998). AtPUMP: an Arabidopsis gene encoding a plant uncoupling mitochondrial protein. FEBS Letters, 429: 403-406.

16. Režzička $M$, Novák $P$, Žáčková $M$, Costa ADT, Vercesi AE, \& J ežek P (1999). Plant uncoupling mitochondrial protein is the product of StUCP gene. Proceedings of the XXVIII Annual Meeting of the Brazilian Society for Biochemistry and Molecular Biology, Caxambu, MG, Brazil, May 2225, A13, 3.

17. Klingenberg $M$ (1990). Mechanism and evolution of the uncoupling protein of brown adipose tissue. Trends in Biochemical Sciences, 15: 108-112.

18. Nedergard J \& Cannon B (1992). The uncoupling protein thermogenin and mitochondrial thermogenesis. In: Ernster L (Editor), Molecular Mechanisms in Bioenergetics. Vol. 23. Elsevier Science, London, 385-420.

19. J ežek $P \&$ Garlid KD (1997). Mammalian mitochondrial uncoupling proteins. International J ournal of Biochemistry and Cell Biology, 30: 1163-1168.

20. Fleury C, Neverova M, Collins S, Raimbault $\mathrm{S}$, Champigny O, Levi-Meyrueis $\mathrm{C}$, Bouillaud F, Seldin MF, Surwit RS, Ricquier D \& Warden CH (1997). Uncoupling protein-2: a novel gene linked to obesity and hyperinsulinemia. Nature Genetics, 15: 269-272.

21. Boss O, Samec S, Paoloni-Giacobino A, Rossier C, Dullo A, Seydoux J, Muzzin P \& Giacobino J -P (1997). Uncoupling protein-3: a new member of the mitochondrial carrier family with tissue specific expression. FEBS Letters, 408: 39-42.

22. Mao W, Yu XX, Zhong A, Li W, Brush J, 
Sherwood SW, Adams SH \& Pan G (1999). UCP4, a novel brain-specific mitochondrial protein that reduces membrane potential in mammalian cells. FEBS Letters, 443: 326-330.

23. Sanchis D, Fleury C, Chomiki N, Goubern M, Huang Q, Neverova M, Gregoire F, Easlick J, Raimbault S, Levi-M eyrueis C, Miroux B, Collins S, Seldin M, Richard D, Warden $C$, Bouillaud $F \&$ Ricquier $D$ (1998). BM CP1, a novel mitochondrial carrier with high expression in the central nervous system of humans and rodents, and respiration uncoupling activity in recombinant yeast. J ournal of Biological Chemistry, 273: 34611-34615.

24. J aburek $M$, Vařecha $M$, Gimeno $R E$, Dembski $M$, J ežek $P$, Zhang $M$, Burn $P$, Tartaglia LA \& Garlid KD (1999). Transport function and regulation of mitochondrial uncoupling proteins 2 and 3 . J ournal of Biological Chemistry, 274: 26003-26007.

25. Skulachev VP (1991). Fatty acid circuit as a physiological mechanism of uncoupling of oxidative phosphorylation. FEBS Letters, 294: 158-162.

26. Garlid KD, Orosz DE, Modriansky M, Vassanelli S \& J ežek P (1996). On the mechanism of fatty acid-induced proton transport by mitochondrial uncoupling protein. J ournal of Biological Chemistry, 271: 2615-2620.

27. J ežek P \& Garlid KD (1990). New substrates and competitive inhibitors of the
$\mathrm{Cl}^{-}$translocating pathway of the uncoupling protein of brown adipose tissue mitochondria. J ournal of Biological Chemistry, 265: 19303-19311.

28. J ežek $P \&$ Borecký J (1998). Mitochondrial uncoupling protein may participate in futile cycling of pyruvate and other monocarboxylates. American J ournal of Physiology, 275: C496-C504.

29. Kopecký J , J ežek P, Drahota Z \& Houstek $J$ (1987). Control of uncoupling protein in brown fat mitochondria by purine nucleotides. Chemical modification by diazobenzenesulfonate. European J ournal of Biochemistry, 164: 687-694.

30. J ežek P (1987). Sulfhydryl groups are involved in $\mathrm{H}^{+}$translocation via the uncoupling protein of brown adipose tissue mitochondria. FEBS Letters, 240: 89-93.

31. J ežek $P \&$ Drahota Z (1989). Sulfhydryl groups of the uncoupling protein of brown adipose tissue mitochondria. Distinction between sulfhydryl groups of the $\mathrm{H}^{+}$ channel and the nucleotide binding site. European J oumal of Biochemistry, 183: 89-95.

32. Katiyar SS \& Shrago E (1989). Reconstitution of purified brown adipose tissue mitochondria uncoupling protein: demonstration of separate identity of nucleotide binding and proton translocation sites by chemical probes. Proceedings of the National Academy of Sciences, USA, 86: 2559-2562.
33. Arechaga I, Raimbault $S$, Prieto $S$, LeviMeyrueis C, Zaragoza P, Miroux B, Ricquier D, Bouillaud F \& Rial E (1993). Cysteine residues are not essential for uncoupling protein function. Biochemical J ournal, 296: 693-700.

34. Murdza-Inglis DL, Modriansky M, Patel HV, Woldegiorgis G, Freeman K \& Garlid KD (1994). A single mutation in uncoupling protein of rat brown adipose tissue mitochondria abolishes GDP sensitivity of $\mathrm{H}^{+}$transport. J ournal of Biological Chemistry, 269: 7435-7438.

35. Mayinger $P \&$ Klingenberg $M$ (1992). Labeling of two different regions of the nucleotide binding site of the uncoupling protein from brown adipose tissue mitochondria with two ATP analogs. Biochemistry, 31: 10536-10543.

36. Bouillaud F, Arechaga I, Petit PX, Raimbault S, Levi-Meyrueis C, Casteila L, Laurent M, Rial E \& Ricquier D (1994). A sequence related to a DNA recognition element is essential for the inhibition by nucleotides of proton transport through mitochondrial uncoupling protein. EMBO J ournal, 13: 1990-1997.

37. Nelson DR, Lawson J E, Klingenberg $M \&$ Douglas MG (1993). Site-directed mutagenesis of the yeast mitochondrial ADP/ ATP translocator. J ournal of Molecular Biology, 230: 1159-1170. 